\title{
LEGISLAÇÃO E QUADRO LEGAL DA GESTÃO DE RESÍDUOS SÓLIDOS URBANOS EM MOÇAMBIQUE
}

\author{
Legislation and legal framework of urban solid \\ waste management in Mozambique
}

\author{
Helena Ribeiro* \\ Lina Buque**
}

\section{RESUMO}

Este artigo descreve a base legal que regula a gestão de resíduos sólidos urbanos em Moçambique com a visão focada nas organizações de coleta seletiva e reciclagem. Para tanto, fez-se uso do método analítico-descritivo, utilizando como estratégia metodológica o levantamento bibliográfico e documental em obras de maior relevância sobre o tema abordado, a partir do qual, foi feita uma análise descritiva da legislação e das normas legais. A pesquisa demonstrou que a legislação ambiental apresenta as normas ambientais, contudo, há inadequação dos meios de implementação, por carência de recursos materiais, técnicos, humanos e financeiros. A legislação ambiental moçambicana contém instrumentos importantes para permitir o avanço necessário ao país no enfrentamento dos principais problemas ambientais, sociais e econômicos decorrentes do manejo inadequado dos resíduos sólidos urbanos (RSU). Destaca-se o fato de prever a redução na geração de resíduos, propondo o reuso e o reaproveitamento. Uma lacuna da legislação é que não menciona a pertinência da elaboração de um Plano Estratégico Nacional e/ou Municipal de Resídios Sólidos Urbanos, instrumento estratégico diretor da gestão de RSU, fundamental para que o setor possa dispor de orientações e objetivos claros, bem como de uma estratégia de investimento. A legislação não apresenta instrumentos para propiciar a reciclagem e o reaproveitamento, nem faz referência à participação de organizações de coleta seletiva e reciclagem no sistema de gestão de resíduos sólidos dos municípios, como forma de enfrentamento à pobreza e aos problemas causados pelos resíduos sólidos.

Palavras-chave: Moçambique; Legislação Ambiental; Resíduos Sólidos Urbanos.

* Mestre e Doutora em Geografia; Livre-docente em Saúde Pública. Professora Titular, Diretora, Faculdade de Saúde Pública, Universidade de São Paulo. São Paulo/SP-Brasil. E-mail: lena@usp.br

** Mestranda em Ciência Ambiental, Universidade de São Paulo. Bolsista da Fundação Ford para realização deste trabalho. Maputo - Moçambique.E-mail: Ibuque@usp.br

Texto recebido em 01/11/2012. Revisado em: 01/03/2013. Aprovado em 04/03/2013. 


\begin{abstract}
This article describes the legal framework that regulates urban solid waste management in Mozambique, with focus on recycling organizations. The methodology of the research was based on analysis of Mozambican environmental laws and secondary data available in newsletters and other documents. Between the positive aspects of Mozambican environmental legislation, it is highlighted the fact that the law emphasizes reuse and return of residues. A gap on law is the lack of reference to participation of organizations dedicated to benefit and to recycle urban solid waste. There is no foresight of the municipality financing recycling projects/programs developed by scavengers. The research shows that formulation of public policies of solid waste must consider articulating and integrating recycling organizations of waste management as a local solution for the environmental and social problems faced by the municipality.
\end{abstract}

Keywords: Environmental Legislation; Mozambique; Urban Solid Waste.

\title{
Introdução
}

Após a luta pela independência (1975), as cidades de Moçambique passaram a estar administrativamente dependentes do Governo Central, principalmente no que diz respeito aos recursos financeiros. Muitas estruturas administrativas da época dos portugueses mantiveram-se até os dias de hoje. O crescimento das cidades moçambicanas não foi acompanhado pela provisão de infraestrutura e de serviços urbanos, entre eles os serviços públicos de saneamento básico, que incluem o abastecimento de água potável, a coleta e tratamento de esgoto sanitário, a estrutura para a drenagem urbana e o sistema de gestão e manejo dos resíduos sólidos. ${ }^{(1)}$ Segundo o Relatório de Desenvolvimento Humano 2011 Sustentabilidade e Equidade: Um futuro melhor para todos, publicado pelas Nações Unidas, entre 1990 e 2011 o valor do Índice de Desenvolvimento Humano (IDH) de Moçambique aumentou de 0,200 para 0,322. Não obstante o aumento continuado no valor de IDH, Moçambique classifica-se em $184^{\circ}$ lugar, de um total de 187 países. ${ }^{(2)}$

Os resíduos sólidos domiciliares coletados são depositados em lixeiras oficiais ou clandestinas sem nenhum tratamento. Desse total, $60 \%$ podem potencialmente ser reaproveitados, desde que separados na fonte geradora e coletados

\footnotetext{
1 MAPUTO (Município). Plano Director da Gestão de Resíduos Sólidos Urbanos da Cidade de Maputo. Maputo, 2008.

2 PROGRAMA DAS NAÇÕES UNIDAS PARA O DESENVOLVIMENTO (PNUD) Moçambique. Thomas Kring. Moçambique e o Índice de Desenvolvimento Humano (IDH) 2011. Maputo, Publicado pela Unidade de Análise de Políticas e Economia (EPAU). Disponível em: <http://www.undp. org.mz/en/Publications/National-Reports/Mocambique-e-o-Indice-de-Desenvolvimento-HumanoIDH-2011>. Acesso em: 05 dez. 2011.
} 
seletivamente para serem encaminhados para reaproveitamento e reciclagem, poupando recursos naturais e promovendo assim o aumento da vida útil dos aterros e a geração de trabalho e renda.

A rápida urbanização, o crescimento de bairros sem nenhum serviço básico, os fluxos migratórios internos, entre outros fatores, têm desafiado a administração pública a enfrentar novas realidades. São cada vez mais comercializados e usados nas lojas e nos mercados, em substituição a cestos de material natural e tecidos, produtos plásticos, especialmente os sacos. O aumento exponencial no uso do plástico em objetos de uso diário, mais econômico em relação aos mesmos produtos fabricados com madeira ou metal, tem sido causa de poluição, destacando-se o aumento de lixo nas ruas e entupimento de canais de drenagem de águas pluviais.

Apenas uma ínfima percentagem destes resíduos é reaproveitada e reciclada, embora as populações, geralmente rurais, tenham o hábito de reaproveitar materiais como garrafas/garrafões de plástico e vidro. Iniciativas de atividade de coleta e venda de recicláveis no mercado moçambicano são reduzidas devido à falta de incentivos econômicos e escassez de indústrias transformadoras. Um fator fundamental para o sucesso dos projetos de coleta seletiva é o reconhecimento dos catadores de materiais recicláveis como atores centrais desta atividade. Contudo, em Moçambique, os catadores são vistos como marginais, como sendo um dos agentes do aparecimento do lixo fora dos depósitos (containers), que, na busca de materiais recicláveis e alimento, entre outros, revolvem os resíduos depositados nos containers, prejudicando a ação de limpeza do município. Saliente-se que a coleta de materiais recicláveis nas ruas, em grande parcela, é feita por catadores autônomos, visto associações de catadores serem muito recentes no país e não existir um movimento nacional ou associação moçambicana de catadores. Os poucos catadores que se encontram associados são os que pertencem às cooperativas ou associações de coleta seletiva. Apesar do triste cenário dos catadores de rua, no âmbito dos esforços visando ao combate à proliferação de resíduos sólidos, eles poderiam ter um papel importante, desde que reconhecidos pela legislação.

Com a introdução das autarquias, em 1999, foi estabelecido um novo marco regulatório de gestão urbana e as autoridades municipais se encarregam do gerenciamento dos resíduos sólidos urbanos, bem como do cumprimento da legislação pertinente a sua área de jurisdição.

De acordo com o Recenseamento Geral de População e Habitação, realizado em 2007, publicado em 2010, Moçambique tem uma população de cerca de 20 milhões de habitantes, que representa um aumento de 27,8\% em relação a 1997. Ainda segundo o censo, $30 \%$ da população está concentrada nas cidades e o restante em áreas rurais. Os principais centros urbanos com grande concentração 
populacional são Maputo, Matola e cidade da Beira. ${ }^{(3)}$ Em Moçambique, todos os municípios destinam seus resíduos sólidos à disposição a céu aberto, nas denominadas lixeiras ou lixão. Nenhum município do país ainda resolveu satisfatoriamente o gerenciamento dos resíduos sólidos urbanos e o modelo tradicional de gestão apresenta uma série de problemas, sem trazer soluções.

Estima-se que, no país, pouco mais de um terço da população tenha acesso à água potável e pouco mais de $45 \%$ da população tenha acesso ao saneamento adequado. Grande parte das cidades do país apresenta rede de esgoto com ligações domiciliares, embora o uso de fossas sépticas seja comum nas zonas periféricas. No meio rural, abundam latrinas melhoradas e/ou tradicionais. As metas do país são atingir $70 \%$ da cobertura de abastecimento de água potável até 2015. A meta para o saneamento rural é atingir 50\%, servindo 8,4 milhões de pessoas, e para as zonas urbanas é atingir $80 \%$, servindo 6,1 milhões de pessoas com saneamento adequado. ${ }^{(4)}$

Atualmente, a taxa de lixo ou de limpeza é cobrada, usando o sistema de faturação da Eletricidade de Moçambique. Portanto, todos os usuários de energia elétrica, no sistema pré-pago (Credelec) ou no pós-pago (Contrato), são obrigados a pagar a taxa de lixo quando pagam as suas contas de consumo de energia elétrica, uma vez que a taxa de lixo vem inclusa, mensalmente, na fatura ou no recibo de Credelec.

Considerando a crescente atenção dada à problemática causada pelos resíduos sólidos em Moçambique, iniciaram-se em 2006 (em Maputo), as primeiras atividades de valorização dos resíduos sólidos, dentre eles o plástico, o vidro, o papel, o metal e o resíduo orgânico vegetal. Alguns anos mais tarde, estas atividades levaram à criação de centros para tratamento e valorização de resíduos sólidos, oferecendo oportunidade de trabalho, aumento do rendimento e de sensibilização ambiental. O tema de resíduos sólidos abre possibilidades de formulação de políticas públicas que reduzam os impactos sobre o meio ambiente e promovam inclusão social e geração de renda. Este artigo descreve a base legal que regula a gestão de resíduos sólidos urbanos em Moçambique, com a visão focada nas organizações de coleta seletiva e reciclagem.

\footnotetext{
3 INSTITUTO NACIONAL DA ESTATíSTICA (INE). Recenseamento Geral de População e Habitação, 2007. Maputo, 2010. Disponível em: <http://www.ine.gov.mz/home_page/censo07/>. Acesso em: 10 nov. 2011.

${ }^{4}$ UNICEF MOÇAMBIQUE E MISA-MINISTÉRIO DA SÁUDE. Água e saneamento: análise da cobertura jornalística e recomendações para os media. Maputo, 2008. Disponível em: <http://www. unicef.org/mozambique/UNICEF-MISA_Analise_de_Imprensa-_agua_e_Saneamento_COVER. pdf>. Acesso em: 15 nov. 2011.
} 


\section{Enquadramento legislativo da gestão de resíduos sólidos urbanos em Moçambique}

Nesta secção é apresentada a legislação moçambicana aplicável a resíduos sólidos urbanos desde os comandos institucionais, regulamentos e posturas municipais. Um maior destaque é dado ao Decreto n. ${ }^{\circ} 13 / 2006$, de 15 de junho de 2006, Regulamento sobre Gestão de Resíduos Sólidos, por ser o instrumento que aborda com mais detalhe o tema dos resíduos sólidos. Entretanto, há outros instrumentos legais e normativos que guardam relações com o tema resíduo sólido, os quais, em conjunto, vêm preenchendo a lacuna causada pela inexistência de uma política mais abrangente de resíduos sólidos urbanos. Destacam-se:

- Lei n. ${ }^{\circ}$ 2/97, de 18 de Fevereiro de 1997, Lei das Autarquias Locais;

- Lei n. ${ }^{\circ}$ 11/97, de 31 de Maio de 1997, Lei das Finanças e Patrimônio das autarquias locais;

- Decreto n. ${ }^{\circ} 8 / 2003$, de 18 de Fevereiro de 2003, Regulamento sobre a Gestão de Lixos Biomédicos;

- Decreto n. ${ }^{4}$ 45/2004, Regulamento sobre o Processo de Avaliação de Impacto Ambiental;

- Decreto n. ${ }^{\circ}$ 11/2006, de 15 de Junho de 2006, Regulamento sobre Inspeção Ambiental;

- Decreto n. ${ }^{\circ} 13$ /2006, de 15 de Junho de 2006, Regulamento sobre a Gestão de Resíduos Sólidos;

- Resolução n. ${ }^{\circ}$ 86/AM/2008, de 22 de Maio de 2006, Postura de Limpeza de Resíduos Sólidos Urbanos no Município de Maputo; e

- Plano Diretor da Gestão de Resíduos Sólidos do Município de Maputo.

O país carece de uma política nacional de resíduos sólidos que contemple de forma ampla as diversas questões que envolvem o gerenciamento destes resíduos. Entretanto, é importante salientar a criação do Ministério para Coordenação da Ação Ambiental (MICOA), como órgão consultivo e deliberativo responsável por assessorar e propor ao Conselho de Governo, diretrizes de políticas governamentais para o meio ambiente e para os recursos naturais. Há, ainda, na legislação, instrumentos jurídicos para auxiliar os municípios na gestão dos resíduos sólidos: o Plano Diretor de Resíduos Sólidos; a Lei de Uso e Ocupação do Solo; Código de Postura de Limpeza, entre outras disposições.

A constituição da República de Moçambique, de 2004, não introduz o meio ambiente em capítulo próprio, porém, garante o direito de todos os moçambicanos a um meio ambiente ecologicamente equilibrado e essencial à sadia qualidade 
de vida. Contempla o meio ambiente no artigo $90,{ }^{(5)}$ em que declara o meio ambiente de uso comum de todos e impõe, tanto ao poder público, quanto à coletividade, o dever de zelar pela sua proteção. Observa-se, dessa maneira, a preocupação relacionada a uma qualidade ambiental sustentável. Contudo, observa-se que temas específicos, sobre os resíduos sólidos urbanos, não foram contemplados na Constituição da República.

Em 1995, o Governo aprovou a Resolução n. ${ }^{\circ}$ 5/95, de 3 de Agosto, a Política Nacional do Ambiente. Da aplicação desta política resultaram ações concretas para que o país, pela primeira vez, desse um passo fundamental na concretização de uma política de resíduos sólidos urbanos. A Política Nacional do Ambiente adotou a Gestão do Ambiente Urbano e, dentro desta, a gestão de resíduos domésticos e hospitalares, como prioridade de intervenção. A estratégia foi descentralizar a competência da gestão ambiental urbana para os municípios, capacitando-os na gestão de resíduos sólidos domésticos e hospitalares, visando melhorar o sistema de recolha, tratamento e disposição dos resíduos e introduzir mecanismos para participação das comunidades na gestão dos resíduos sólidos.

Embora a política não estabeleça metas para o encerramento de todos os lixões no país, propõe a criação e o gerenciamento de novas áreas de disposição final de resíduos sólidos, introduzindo sistemas de tratamento e reciclagem. A Política Nacional do Ambiente vai além e propõe a introdução, aos cidadãos, de mecanismos para a prática de separação dos resíduos sólidos. Sugere, em médio e longo prazos, a adoção de medidas legislativas que obriguem os poluidores a procederem à reciclagem dos seus resíduos. Pode-se se entender com isto que a política propõe a criação de aterros sanitários (domésticos e industriais), infraestruturas de valorização, eliminação e disposição de resíduos (domésticos, químicos e biológicos perigosos) e criação de sistemas de coleta seletiva. A Política abriu caminho, também, para a constituição e o licenciamento de entidades gestoras de fluxos especiais de resíduos.

Em 1997, foi aprovada pela Assembleia da República a Lei do Ambiente, Lei n. ${ }^{\circ} 20 / 97$, de 1 de Outubro. Esta lei estipula as bases do sistema de prevenção e proteção do ambiente em Moçambique. Esta lei vem definir as bases legais para a utilização e gestão correta do ambiente e seus componentes, com vista à materialização de um sistema de desenvolvimento sustentável no país. A Lei do Ambiente também proíbe a importação de resíduos ou lixos perigosos, salvo o que vier estabelecido em legislação específica. Nela, define-se ambiente como "o meio onde o homem e outros seres vivos vivem e interagem entre si e com o próprio meio e inclui: a) O ar, a luz, a terra e a água; b) Os ecossistemas, a

\footnotetext{
${ }^{5}$ Art. 90 (Direito ao ambiente). 1. Todo o cidadão tem o direito de viver num ambiente equilibrado e o dever de o defender. 2. O Estado e as autarquias locais, com a colaboração das associações de defesa do ambiente, adoptam políticas de defesa do ambiente e velam pela utilização racional de todos os recursos naturais. MOÇAMBIQUE. Portal do Governo de Moçambique. Constituição da República de Moçambique. Disponível em: <http://www.portaldogoverno.gov.mz/Legisla/ constituicao_republica/>. Acesso em: 19 jan. 2014.
} 
biodiversidade e as relações ecológicas; c)Toda matéria orgânica e inorgânica; d) Todas as condições sócio-culturais que afetam a vida das comunidades."

O conceito de ambiente adotado pela lei é um conceito amplo, abrangendo não só os elementos naturais, também designados componentes ambientais, mas também os artificiais (como o meio urbano), cultural (patrimônio cultural, bens relevantes a comunidades locais) e laboral (salubridade do meio ambiente de trabalho).

Sendo os resíduos sólidos um fator determinante ou potencialmente determinante de saúde pública e problemas ambientais, não podem ser olhados com indiferença. Invoca-se a validade dos princípios de defesa ambiental em especial da prevenção e o do poluidor-pagador. Nos termos do artigo $9^{\circ}$ da Lei do Ambiente, optou-se por se impor uma proibição de poluir, prevendo, expressamente, que:

Não é permitida, no território nacional, a produção, o depósito no solo e no subsolo, o lançamento para a água ou para a atmosfera, de quaisquer substâncias tóxicas e poluidoras, assim como a prática de atividades que acelerem a erosão, a desertificação, o desflorestamento, ou qualquer outra forma de degradação do ambiente, fora dos limites legalmente estabelecidos.

A lei prevê que está também proibida "qualquer outra forma de degradação do ambiente, que não somente aquelas especificamente consagradas na Lei”. A aplicação desses princípios permite deslocar a visão tradicional da natureza jurídica que conecta os resíduos sólidos urbanos com aqueles que o geram, e com aquele que tem a obrigação de dar-Ihes uma destinação adequada ${ }^{(6)}$.

Como instrumentos de prevenção do dano ambiental, a Lei do Ambiente estabelece que seja o Governo, através do Ministério para Coordenação da Acção Ambiental, a quem cabe a tarefa de elaborar e executar as políticas em matéria ambiental, como tal, é em sede administrativa que a prevenção e precaução do dano devem ser primeiramente levadas em consideração e defendidas. A Lei do Ambiente aponta, também, nesse sentido, ao identificar o licenciamento ambiental, a avaliação de impacto ambiental e as auditorias ambientais.

Outro documento aprovado que guarda alguma relação, embora que exígua, com residuos sólidos urbanos é o Decreto Ministerial n. ${ }^{\circ}$ 45/2004, de 29 de Setembro, que aprova o Processo de Avaliação de Impacto Ambiental. Estabelece critérios para licenciamento ambiental de atividades poluidoras e institui a obrigatoriedade de realização de Estudos e Relatórios de Impacto Ambiental (EIA/RIMA).

A Lei das Autarquias locais, Lei n. ${ }^{\circ}$ /97, de 18 de Fevereiro, garante aos municípios competência para a busca do desenvolvimento local com qualidade

\footnotetext{
${ }^{6}$ SILVEIRA, Paula de Castro. Algumas considerações sobre a Lei do Ambiente em Moçambique. Beira, 2010. GEOUSP. Disponível em: <http://www.geografia.fflch.usp.br/publicacoes/Geousp/ Geousp14/Geousp_14_intercambio1.htm>. Acesso em: 13 set. 2011.
} 
ambiental, conferida da seguinte forma: autonomia quanto ao licenciamento ambiental e controle dos impactos ambientais locais; criação e manutenção de Parques e Áreas Verdes; promoção da educação ambiental e planejamento ambiental; e aumento de arrecadação, através de taxas de licenciamento e multas.

A fim de alcançar tais competências, os municípios contam com a cooperação do Estado e participação dos organismos da sociedade civil, tendo em vista a máxima eficiência e a adequada proteção ambiental e a saúde pública. Para compor a base do sistema de planejamento municipal e efetivar suas competências, são exigidos aos municípios: plano diretor; plano plurianual: estabelece as diretrizes, objetivos e metas da administração pública para as despesas do município; diretrizes orçamentárias: compreendem metas e prioridades da administração pública e despesas de capital para o exercício subsequente; orçamentos anuais: abrangem o orçamento fiscal, de investimento e seguridade social.

Com os instrumentos normativos de planejamento adotados pelos municípios, estes expressam sua autonomia administrativa para organizar e prestar os serviços públicos de interesse local, incluindo a limpeza urbana. Estes englobam: prover, sobre limpeza de vias públicas, remoção e destinação final dos resíduos domiciliares; tratamento e distribuição da água; coleta e tratamento de esgotos; obras de drenagem e limpeza de bueiros e córregos, vigilância sanitária, entre outros. Os municípios vinculam a organização dos serviços de limpeza urbana à administração direta, e os serviços de limpeza encontram-se ligados a uma direção/secretaria do governo municipal, a Direcção de Serviço Municipal de Saúde e Salubridade.

A título de exemplo, da legislação municipal relacionada com o tema em estudo, destaca-se a Resolução n. ${ }^{\circ}$ 86/AM/2008, de 22 de Maio, Postura de Limpeza de Resíduos Sólidos Urbanos no Município de Maputo. Esse documento define o Sistema de Limpeza do Municipio de Maputo, integrando as componentes varredura e gestão de Resíduos Sólidos Urbanos (RSU). Aplica-se a todas as atividades públicas e privadas que, direta ou indiretamente, influenciam na componente de limpeza do município. Visa o estabelecimento do quadro de princípios e normas gerais do Sistema de Limpeza de RSU. Não se aplica a resíduos biomédicos e perigosos, sujeitos a regulamentação específica. A justificativa para aprovação do documento, por parte do município de Maputo, era a de que o quadro legislativo do município sobre gestão de resíduos sólidos urbanos encontrava-se disperso, não harmônico, insuficiente e desajustado em relação à legislação nacional em vigor no país, bem como não havia qualquer perspectiva de aproveitamento econômico dos RSU e de envolvimento ou integração do setor privado no respectivo processo de gestão. ${ }^{(7)}$

\footnotetext{
7 MOÇAMBIQUE. Assembleia Municipal da cidade de Maputo. Decreto n.o 86/AM/2008 de 22 de Maio. Aprova a Postura de limpeza de resíduos sólidos urbanos do município de Maputo. Boletim da República, Maputo, III série n.49, 5 dez. 2008.
} 


\section{Decreto n. ${ }^{\circ} 13 / 2006$, de 15 de julho, Regulamento sobre a Gestão de Resíduos Urbanos}

Havendo necessidade de se definir o quadro legal moçambicano para se processar a gestão de resíduos resultantes das atividades humanas, foi aprovado, a 15 de Julho de 2006, o Decreto n. ${ }^{\circ}$ 13/2006, Regulamento sobre a Gestão de Resíduos. Ficou como competência do MICOA aprovar as normas que se mostrem necessárias para assegurar a aplicação do regulamento. $O$ regulamento sobre resíduos sólidos é uma ferramenta legal indispensável para se promover uma adequada gestão dos resíduos no país. Trata o regulamento de estabelecer as diretrizes mínimas para que se equacione um dos mais graves problemas ambientais urbanos em Moçambique. As deficiências ainda são enormes e o caminho para que se chegue a condições ambientalmente sustentáveis, socialmente justas e economicamente viáveis em relação aos resíduos sólidos ainda é bastante longo.

O decreto institui a regulamentação sobre a gestão de resíduos sólidos em nível nacional, dispondo sobre seus princípios, objetivos e instrumentos, bem como sobre as diretrizes relativas à gestão integrada, ao gerenciamento de resíduos sólidos, incluídos os perigosos, às responsabilidades dos geradores e do poder público e aos instrumentos econômicos aplicáveis. Estão sujeitas, à observância desta lei, as pessoas físicas, ou jurídicas, de direito público ou privado, responsáveis, direta ou indiretamente, pela geração de resíduos sólidos e as que desenvolvam ações relacionadas à gestão integrada, ou ao gerenciamento de resíduos sólidos. A lei não se aplica aos rejeitos radioativos, resíduos bio-médicos; águas residuais, com exceção das que contenham características de risco descritas nos anexos III e IV do regulamento e resíduos perigosos sujeitos a regulamentação específica.

\subsection{Definições}

No primeiro título da lei, estão incluídas, no capítulo I, disposições gerais sobre o objeto e o campo de aplicação do regulamento. Deve ser destacado que a lei direciona-se tanto ao setor público quando aos empreendedores privados e a todos aqueles envolvidos, direta ou indiretamente, na geração, gestão ou gerenciamento de resíduos sólidos, incluindo o cidadão. Ainda no mesmo capítulo, tem-se um conjunto de definições a serem empregadas ao longo do texto. Entre a série de definições presentes no artigo 1..$^{\circ}$, dispostas em ordem alfabética, cabe destacar as seguintes: aproveitamento ou valorização, detentor, eliminação e resíduos:

a) Aproveitamento ou Valorização - utilização de resíduos ou componentes destes, por meio de processos de refinação, recuperação, regeneração, reciclagem, reutilização ou qualquer outra acção (que conste da lista do Anexo VI) tendente à obtenção de matérias-primas secundárias, com o objetivo da reintrodução dos 
resíduos nos circuitos de produção e ou consumo em utilização análoga, sem alteração dos mesmos.

d) Detentor - o produtor dos resíduos ou outra pessoa ou entidade que detém a sua posse ou controle.

e) Eliminação - o recurso a quaisquer das operações especificadas no Anexo VI do regulamento.

l) Resíduos - as substâncias ou objetos que se eliminam, que se tem a intenção de eliminar ou que se é obrigado por lei a eliminar, também designados por lixos.

Esta lei omite definições de conceitos importantes aplicados à gestão de resíduos sólidos, entre outras, destacam-se as seguintes: destinação final ambientalmente adequada, disposição ambientalmente adequada, geradores de resíduos sólidos, coleta seletiva, reciclagem.

Cabe atenção para a diferenciação entre os conceitos de destinação final e disposição final, conceitos não assumidos pela lei. Consideram-se ambientalmente adequados, como destinação dos resíduos, a reutilização, a reciclagem, a compostagem, a recuperação e o aproveitamento energético, bem como outras destinações admitidas pelos órgãos públicos competentes. A disposição final, por sua vez, é entendida como a distribuição ordenada dos rejeitos em aterros, desde que observadas as regras ambientais e de saúde pública pertinentes. ${ }^{\left({ }^{(8)}\right.}$

O conceito "detentor", trazido pelo regulamento, subentende geradores de resíduos. No entanto, o conceito detentor/geradores de resíduos é amplo, abrangendo todas as pessoas físicas ou jurídicas, públicos ou privados cujas atividades geram resíduos sólidos. Cabem no conceito detentor aqueles que desenvolvem atividades como tratamento de resíduos.

Cabe, também, distinguir gerenciamento e gestão de resíduos sólidos. O gerenciamento diz respeito às etapas de coleta, transporte, transbordo, tratamento e destinação final ambientalmente adequada dos rejeitos. Apresenta-se, assim, lógica processual ou operacional. O gerenciamento pode dizer respeito apenas a tipo determinado de resíduos. Por sua vez, a gestão integrada engloba o planejamento e a coordenação de todas as etapas insertas no gerenciamento e, também, a inter-relação das dimensões políticas, econômica, ambiental, cultural e social envolvidas. ${ }^{(9)}$

No artigo $2 .^{\circ}$, tem se, como objeto do regulamento, o estabelecimento das regras relativas à produção, ao depósito no solo e no subsolo, ao lançamento para água ou para atmosfera, de quaisquer substâncias tóxicas e poluidoras,

\footnotetext{
${ }^{8}$ ARAÚJO, S.; JURAS, I. Comentários à lei dos resíduos sólidos: Lei n. 12.305, de 2 de agosto de 2010 (e seu regulamento). São Paulo: Ed. Pillares, 2011.

9 RIBEIRO, H.; JACOBI, P.; BESEN, G.; GUNTHER, W.; DEMAJOROVIK, J.; VIVEIROS, M. Coleta seletiva com inclusão social: cooperativismo e sustentabilidade. São Paulo: Annablume. 2009.
} 
assim como a prática de atividades poluidoras, que acelerem a degradação do ambiente, com vista a prevenir ou minimizar os seus impactos negativos sobre a saúde e o ambiente.

A lei não traz um artigo especificando os seus objetivos. Contudo, entende-se que a não geração, redução, reutilização, reciclagem e tratamento dos resíduos, agregados à disposição final ambientalmente adequada dos rejeitos, podem ser tomados como o objetivo síntese das disposições gerais trazidas pelo Decreto $n$. $^{\circ}$ 13/2006. De forma direta ou indireta, a lei tem esse propósito como subjacente a praticamente todas as suas determinações.

O regulamento deveria trazer, para seus objetivos, entre outros, incentivo aos municípios à criação e à contratação de associações e/ou cooperativas de coleta, triagem e beneficiamento de matérias recicláveis para execução das atividades de coleta, processamento e comercialização de resíduos urbanos recicláveis ou reutilizáveis; desenvolvimento de sistemas de gestão ambiental e empresarial voltados para a melhoria dos processos produtivos; aproveitamento energético, assim como o estímulo à rotulagem ambiental e ao consumo sustentável.

\subsubsection{Classificação dos Resíduos}

No artigo $5 .^{\circ}$, consta a classificação geral dos resíduos sólidos. Há dois tipos de classificação, pela origem e pela periculosidade. Na classificação segundo origem, tem se: resíduos domiciliares, vindos de atividades domésticas; resíduos de limpeza urbana, decorrentes da varrição, limpeza de espaços públicos e serviços conexos; resíduos de estabelecimentos comerciais, gerados nessas atividades e não caracterizados como de limpeza urbana, de serviço de saneamento básico, de serviços de saúde, de construção civil ou de transportes. Os resíduos sólidos urbanos reúnem os resíduos domiciliares e os resíduos de limpeza urbana.

Por sua vez, na classificação quanto à periculosidade, tem se: resíduos perigosos, assim considerados em razão de suas características de inflamabilidade, corrosividade, reatividade, toxicidade, patogenicidade, carcinogenicidade, teratogenicidade ou mutagenicidade; e resíduos não perigosos. Seja na tipologia consoante à origem, seja na ponderação da periculosidade, as classes de resíduos estabelecidas pelo regulamento refletem o entendimento de que cada uma delas demanda procedimentos particulares em seu gerenciamento.

\subsection{Plano de gestão de resíduos}

Embora não conste do Decreto n. ${ }^{\circ}$ 13/2006 referencia a instrumentos do regulamento, podem-se apontar os seguintes: os planos de resíduos sólidos; os inventários e os sistemas de declaração semestral de resíduos sólidos; o monitoramento e a fiscalização ambiental; a educação ambiental e o cadastro 
nacional de operadores de resíduos perigosos. No artigo $7 .^{\circ}$, destaca-se a abordagem sobre planos de gestão de resíduos. O texto, muito breve e geral, destaca a obrigação das entidades públicas ou privadas que desenvolvem atividades relacionadas com a gestão de resíduos, de elaborar um plano de gestão dos resíduos por elas geridos, antes do início da sua atividade. O referido plano tem a validade de cinco anos.

O texto não traz normas sobre o gerenciamento, nem impõe responsabilidades nesse sentido tanto ao poder público, em seus diferentes níveis, quanto aos empreendedores privados. Não há menção da obrigação de se elaborar um plano nacional e ou municipal de resíduos sólidos/plano estratégico para resíduos sólidos urbanos. No entanto, um plano nacional é fundamental por diagnosticar a situação do país em relação aos resíduos sólidos, incluindo metas de redução, reutilização, reciclagem, entre outras, com vistas a reduzir a quantidade de resíduos e rejeitos encaminhados para disposição final.

Ainda neste contexto, o artigo sobre plano de gestão de resíduos não faz menção a metas para a eliminação e recuperação de lixões, associadas à inclusão social e à emancipação econômica de catadores de materiais reutilizáveis e recicláveis; à criação de um aterro sanitário para resíduos sólidos urbanos, bem como a programas e projetos de reaproveitamento de resíduos.

Cumpre perceber que os empreendedores privados, que operam com resíduos perigosos, são obrigados por lei a declarar, semestralmente, ao Ministério, para a Coordenação da Acção Ambiental, a sua produção de resíduos. O sistema de declaração semestral de resíduos sólidos reúne as informações sobre a execução dos planos de gerenciamento de resíduos sólidos, que constituem atribuições de todos aqueles empreendedores, públicos ou privados, cujas atividades geram determinados tipos de resíduos, especificados pelo anexo IV do regulamento. Contudo, apesar da obrigação da declaração dos resíduos, não consta do regulamento a determinação de elaboração de inventário municipal de resíduos sólidos.

Ainda no âmbito dos planos, o regulamento impõe a elaboração de plano de gerenciamento de resíduos sólidos a todas as entidades públicas ou privadas que desenvolvem atividades relacionadas com a gestão de resíduos. Assim, no plano, devem constar: descrição do empreendimento ou atividade; diagnóstico dos resíduos sólidos abarcados pelo plano, incluindo origem, volume e caracterização dos resíduos, assim como possíveis passivos ambientais relacionados a esses resíduos; medidas saneadoras desses passivos ambientais; e ações preventivas e corretivas a serem executadas nas situações de gerenciamento incorreto ou acidentes.

\subsection{Capítulo IV - Infrações}

O capítulo contempla diferentes tipos de vedações: o embaraço ou obstrução, sem justa causa, à realização das atividades de fiscalização às entidades competentes para o efeito nos termos deste regulamento; A não observância 
do disposto nos artigos $7 .^{\circ}, 8^{\circ}, 9 .^{\circ}, 10 .^{\circ}$ e 14 ; o não cumprimento das recomendações exaradas no âmbito de um processo de auditoria ambiental pública, a não observância das disposições estipuladas no capítulo III.

\section{Discussão}

A legislação ambiental moçambicana contém instrumentos importantes para permitir o avanço necessário ao país no enfrentamento dos principais problemas ambientais, sociais e econômicos decorrentes do manejo inadequado dos resíduos sólidos urbanos. Destaca-se o fato de prever a redução da geração de resíduos, propondo o reuso e o reaproveitamento. Impõe que empresas públicas ou privadas elaborem seus planos de gerenciamento de resíduos sólidos. Uma lacuna da legislação é que esta não menciona a pertinência da elaboração de um Plano Estratégico Nacional e/ou Municipal de Resíduos Sólidos Urbanos. Este é instrumento estratégico diretor da gestão de resíduos sólidos urbanos, fundamental para que o setor possa dispor de orientações e objetivos claros, bem como de uma estratégia de investimento que confira coerência, equilíbrio e sustentabilidade à intervenção dos vários agentes diretamente envolvidos.

Estudos de base que permitam elaborar uma sólida proposta deverão incidir sobre aspectos específicos, como tecnologias de tratamento de resíduos, sistema tarifário vigente e os custos associados aos diferentes modelos de gestão de RSU, bem como realização de sessões de debate entre especialistas do setor. A proposta deve resultar de um processo muito participativo, para um setor de tanta complexidade. Afigura-se relevante a consulta dos principais agentes ligados à problemática dos RSU, nomeadamente, o poder público municipal, organizações não governamentais de ambiente, associações de catadores, bem como outras entidades e organizações intervenientes, ou seja, agentes de cujo envolvimento depende indiscutivelmente o sucesso deste plano. Deve-se, também, promover um processo de auscultação dos agentes interessados através de um processo de consulta prévia destas entidades. Igualmente importante é o papel dos cidadãos no setor, cada vez menos como produtores passivos e mais como consumidores responsáveis, com influência clara no domínio da prevenção e como agentes decisivos da gestão de resíduos, designadamente, por via de adesão aos esquemas de coleta seletiva.

A legislação ambiental não apresenta instrumentos para propiciar a reciclagem e reaproveitamento, nem faz referencia à participação de organizações de coleta seletiva e reciclagem no sistema de gestão de resíduos sólidos dos municípios como forma de enfrentamento à pobreza e aos problemas causados pelos resíduos sólidos. Também não apresenta previsão de financiamento para municípios que desenvolvam projetos/programas de coleta seletiva e reciclagem. A relevância do papel das organizações engajadas na recuperação de resíduos e na redução dos impactos ambientais a eles associados não está refletida nos diferentes pontos da legislação. Esta poderia trazer diversos benefícios para o 
país, principalmente no tocante à destinação de resíduos, que deveria ser integralmente regularizada num prazo determinado. $O$ arcabouço legal necessita de uma urgente sistematização, com vistas à superação de suas falhas, tais como confusões conceituais, omissões e ambigüidades, fatores que comprometem seu cumprimento, uma vez que carecem da explicitação de parâmetros e critérios para a matéria, embora seja pródigo em comandos genéricos.

Em virtude da presença de entidades dedicadas a atividades de coleta seletiva e reciclagem no país, mesmo que de abrangêcia insignificante, deve o poder local proceder à implantação de programas/projetos de coleta seletiva, reciclagem e compostagem, através de formulação de políticas públicas de resíduos sólidos, que contemplem, de forma articulada e integrada, a gestão dos resíduos sólidos, com a participação destes atores, como forma de promover geração de renda, sua inclusão social e evitar desperdício de recursos materiais.

É importante comentar, na opinião das autoras, que os moçambicanos não têm muito conhecimento sobre a questão ambiental, porém nota-se que há uma consciência quanto à necessidade de se preservar o meio ambiente para evitar danos para o próprio homem. A formação de uma consciência ambiental nos cidadãos está diretamente ligada à inexistência (ou quase) de um trabalho de educação ambiental, formal e informal, que dissemine sistematicamente informações ambientais, entre elas a legislação, a todas as camadas da população e a todas as faixas etárias. Contudo, o país tem vindo a implementar uma Estratégia da Educação Cívica/Ambiental na área de gestão de resíduos sólidos urbanos, constituída por campanhas públicas de sensibilização sobre necessidade de mudanças no comportamento e na postura em relação aos resíduos. Pretende-se que haja envolvimento do setor privado na gestão de resíduos sólidos, bem como minimização da produção de RSU, com utilização de medidas de reciclagem, reuso e outras. É importante referir que, para coleta seletiva e reciclagem, o processo da educação ambiental em Moçambique, entre outros, deve integrar o saber como proceder com os diversos tipos de resíduos, tanto no âmbito da população, quanto no dos catadores de materiais recicláveis. Os desafios da educação ambiental vão desde elaboração de proposta ao governo municipal e outros segmentos para realização da educação ambiental e da reciclagem e da disponibilidade de material didático pedagógico adequado.

O exemplo da Educação Cívica citada reflete a necessidade de limpeza urbana, em decorrência da problemática causada pelos RSUs. Apontam-se outros indicadores de despertar de uma maior consciência ambiental e consequente preocupação com a legislação: o crescimento de investimentos públicos na área ambiental em todo país, assim como os recursos privados e internacionais destinados a projetos e programas no setor. Constitui exemplo o Programa de Desenvolvimento Municipal de Maputo - PROMAPUTO I e II; programa, financiado pelo Banco Mundial, que visa o desenvolvimento institucional, planejamento urbano e ambiental incluindo a componente gestão de RSUs. 


\section{Considerações Finais}

A legislação ambiental apresenta as normas ambientais, contudo, há inadequação dos meios de implementação, por carência de recursos materiais, técnicos, humanos e financeiros. Consequentemente, cumpre verificar como o Estado e os demais órgãos responsáveis pela implementação da legislação ambiental vêm desempenhando o seu papel, os recursos de que eles dispõem para isso e como esses recursos vêm sendo aplicados.

Segundo Ribeiro et al, ${ }^{(10)}$ ao se inverter a lógica de marginalização dos catadores, estes passam a integrar, ainda que de forma frágil, o sistema de gerenciamento de resíduos sólidos. Em países latinos, como o Brasil, Colômbia, Peru e México, por exemplo, o crescimento da capacidade de organização dos grupos de catadores foi essencial no processo de interlocução e, aliados aos movimentos sociais, abriram uma nova perspectiva para a relação do poder municipal com os grupos organizados de catadores.

Os projetos de coleta seletiva, em parceria de catadores com os municípios, podem gerar a valorização do trabalho do catador e de outras pessoas desfavorecidas, promovendo a inclusão social e a cidadania. Considerando-se a conjuntura da sociedade de consumo e os diversos impactos gerados, a reciclagem de resíduos sólidos, desde que atendidas todas as condições de segurança e salubridade, especialmente daqueles que manipulam diretamente tais resíduos, desponta como alternativa capaz de minimizar os impactos da disposição dos resíduos no meio ambiente, tornando disponível matéria prima que não implique em novos custos à natureza.

\section{Referências}

ARAÚJO, S.; JURAS, I. Comentários à lei dos resíduos sólidos: Lei n. 12.305, de 2 de agosto de 2010 (e seu regulamento). São Paulo: Ed. Pillares, 2011.

INSTITUTO NACIONAL DA ESTATÍSTICA (INE). Recenseamento Geral de População e Habitação, 2007. Maputo, 2010. Disponível em: <http://www.ine. gov.mz/home_page/censo07/>. Acesso em: 10 nov. 2011.

MAPUTO (Município). Plano Director da Gestão de Resíduos Sólidos Urbanos da Cidade de Maputo. Maputo, 2008.

MOÇAMBIQUE. Assembleia da República. Lei 11/97, de 31 de Maio. Aprova a lei das finanças e património das autarquias locais. Boletim da República, Maputo, 31 maio 1997.

Assembleia da República. Lei 2/97, de 18 de Fevereiro. Aprova a lei das autarquias locais. Boletim da República, Maputo, I série n. 7, 18 fev. 1997.

\footnotetext{
${ }^{10}$ RIBEIRO, H.; JACOBI, P.; BESEN, G.; GUNTHER, W.; DEMAJOROVIK, J.; VIVEIROS, M. Coleta seletiva com inclusão social: cooperativismo e sustentabilidade. São Paulo: Annablume. 2009.
} 
MOÇAMBIQUE. Assembleia Municipal da cidade de Maputo. Resolução n 86/ AM/2008 de 22 de Maio. Aprova a Postura de limpeza de resíduos sólidos urbanos do município de Maputo. Boletim da República, Maputo, III série n.49, 5 dez. 2008.

. Conselho de Ministros. Constituição da República de Moçambique de 19 de Novembro 2004. Boletim da República, Maputo, 2004.

. Conselho de Ministros. Decreto n. ${ }^{\circ} 11 / 2006$, de 15 de Junho. Aprova o regulamento sobre inspecção ambiental. Boletim da República, Maputo, I série n. 24, 15 jun. 2006.

. Conselho de Ministros. Decreto n. ${ }^{\circ}$ 13/2006, de 15 Junho. Aprova o regulamento sobre gestão de resíduos sólidos. Boletim da República, Maputo, n. 24, 15 jun. 2006.

. Conselho de Ministros. Decreto n. ${ }^{\circ} 8 / 2003$, de 18 de Fevereiro. Aprova o regulamento sobre a gestão de resíduos sólidos bio-médicos. Boletim da República, Maputo, I série n. 7, 18 fev. 2003.

Conselho de Ministros. Decreto n. ${ }^{\circ}$ 45/2004 de 29 de Setembro de 2004. Aprova o regulamento sobre o processo de avaliação de impacto ambiental. Boletim da República, Maputo, I série n. 39, 29 set. 2004.

Conselho de Ministros. Lei $n^{\circ} 20 / 97$ de 1 de Outubro. Aprova a lei do ambiente. Boletim da República Maputo, I série n. 40, 01 out. 1997.

Conselho de Ministros. Resolução 5/95 de 3 de Agosto. Aprova a política nacional do ambiente. Boletim da República I série nº 49, Maputo, 3 ago. 1995.

PROGRAMA DAS NAÇÕES UNIDAS PARA O DESENVOLVIMENTO (PNUD) Moçambique. Thomas Kring. Moçambique e o Índice de Desenvolvimento Humano (IDH) 2011. Maputo, Publicado pela Unidade de Análise de Políticas e Economia (EPAU). Disponível em: <http://www.undp.org.mz/en/Publications/ National-Reports/Mocambique-e-o-Indice-de-Desenvolvimento-HumanoIDH-2011>. Acesso em: 05 dez. 2011.

RIBEIRO, H.; JACOBI, P.; BESEN, G.; GUNTHER, W.; DEMAJOROVIK, J.; VIVEIROS, M. Coleta seletiva com inclusão social: cooperativismo e sustentabilidade. São Paulo: Annablume. 2009.

SILVEIRA, Paula de Castro. Algumas considerações sobre a Lei do Ambiente em Moçambique. Beira, 2010. GEOUSP. Disponível em: <http://www.geografia. fflch.usp.br/publicacoes/Geousp/Geousp14/Geousp_14_intercambio1.htm>. Acesso em: 13 set. 2011.

UNICEF MOÇAMBIQUE E MISA-MINISTÉRIO DA SÁUDE. Água e saneamento: análise da cobertura jornalística e recomendações para os media. Maputo, 2008. Disponível em: <http://www.unicef.org/mozambique/UNICEF-MISA_Analise_ de_Imprensa-_agua_e_Saneamento_COVER.pdf>. Acesso em: 15 nov. 2011. 